Publicação organizada pelo Programa de

Mestrado Profissional Stricto Sensu em

Engenharia Civil da Universidade São Judas

Volume 01 - Edição 01

Janeiro - Dezembro de 2018

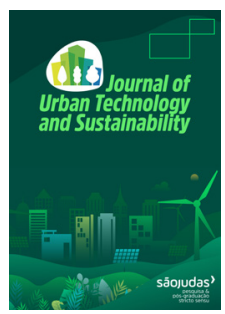

\title{
Avaliação da viabilidade de investimento para instalação de um sistema fotovoltaico em residência unifamiliar na cidade de São Paulo - SP
}

Fabio N. Rodriguesa, Cláudia T. Kniess ${ }^{\mathrm{a},}$, Luciano Caruggi-De-Fariab, Heidy R. Ramosa,c

aprograma de pós-graduação em Cidades Inteligentes e Sustentáveis, Universidade Nove de Julho - UNINOVE, São Paulo, Brasil.

${ }^{\mathrm{b}}$ School of Architecture, Building and Civil Engineering, Loughborough University, Leicestershire, LE11 3TU, UK.

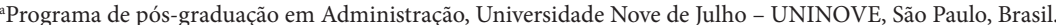

\section{Informações}

Recebido 4 Junho 2018

Manuscrito revisado recebido

17 Agosto 2018

Aceito 20 Agosto 2018

Palavras-chave

Energia solar fotovoltaica

Viabilidade Financeira

Retorno sobre o

investimento

Sustentabilidade

\section{Resumo}

A energia solar fotovoltaica é a energia elétrica obtida por meio da conversão direta da radiação solar. Este tipo de energia vem se popularizando nos últimos anos, especialmente após resolução normativa ANEEL 482/20012, que fundamenta as diretrizes da microgeração e da minigeração distribuída no Brasil. A decisão pela aquisição deste sistema é formada por fatores como conhecimento da tecnologia, conscientização ambiental e custo do sistema que vem diminuindo consideravelmente nos últimos anos. O objetivo deste trabalho é avaliar a viabilidade financeira para instalação de um sistema fotovoltaico em uma residência unifamiliar localizada na cidade de São Paulo. Este trabalho, de natureza qualitativa e abordagem metodológica exploratória e descritiva, utiliza de análises técnicas-econômicas para estimar com precisão as condicionantes envolvidas em uma análise de investimento. Os resultados obtidos demonstram que este investimento de longo prazo é viável, uma vez que o sistema é projetado para funcionar por pelo menos 25 anos.

\section{Evaluation of the financial feasibility to install a photovoltaic system in a unifamiliar house in the city of São Paulo}

\section{Article info}

Received 4 June 2018

Received in revised form 17 August 2018

Accepted 20 August 2018

Keywords

Solar photovoltaic energy

Financial viability

Payback

Sustainability

\begin{abstract}
Photovoltaic energy is generated by the direct conversion of solar radiation into electric energy. It became popular in recent years after updates of Brazilian legislation though ANEEL 482/20012. This resolution allows the residential user to generate their own electricity, supplying the surplus to the distribution network, as well as consuming it when generation is less than production. The decision to acquire this system is made up of factors such as technology knowledge, environmental awareness and cost of the system that has been decreasing in recent years. The aim of this research is to analyze the financial viability for installing a photovoltaic system in a single-family house located in the city of São Paulo. This qualitative research uses a methodological exploratory and descriptive approach with technical-economic analyzes to accurately estimate the constraints involved in an investment analysis. Results demonstrate that this long-term investment is feasible, considering the project is designed to last 25 years.
\end{abstract}

\section{Evaluación de la viabilidad financiera de la instalación de un sistema fotovoltaico en una residencia unifamiliar en la ciudad de São Paulo}

\section{Información}

Recibido 4 Junio 2018

Manuscrito revisado recibido

17 Agosto 2018

Aceptado 20 Agosto 2018

\section{Palabras clave}

Energia solar fotovoltaica

Viabilidad financiera

Retorno sobre la inversión

Sostenibilidad

\section{Resumen}

La energía solar fotovoltaica es la energía eléctrica que se obtiene mediante la conversión directa de la radiación solar. Este tipo de energía se ha popularizado en los últimos años, especialmente después de ANEEL 482/20012, que establece las pautas para la microgeneración y mini generación distribuida en Brasil. La decisión de adquirir este sistema está formada por factores como el conocimiento de la tecnología, la conciencia ambiental y el coste del sistema, que ha disminuíd considerablemente en los últimos años. El objetivo de este trabajo es evaluar la viabilidad financiera para la instalación de un sistema fotovoltaico en una vivienda unifamiliar ubicada en la ciudad de São Paulo. Este trabajo, de carácter cualitativo y enfoque metodológico exploratorio y descriptivo, utiliza análisis técnicoeconómicos para estimar con precisión las condiciones involucradas en un análisis de inversión. Los resultados obtenidos demuestran que esta inversión a largo plazo es factible, ya que el sistema está diseñado para funcionar durante al menos 25 años.

\footnotetext{
* Autor correspondente em: Programa de pós-graduação em Cidades Inteligentes e Sustentáveis, Universidade Nove de Julho, São Paulo, Brasil. E-mail: kniesscl@gmail.com (Cláudia T. Kniess)
} 


\section{Introdução}

Desde a Revolução Industrial, a qualidade de vida e a competitividade dos países são influenciadas por questões energéticas. Diante das atuais preocupações com o meio ambiente, as economias precisam se posicionar quanto ao acesso aos recursos energéticos ponderando seus custos e impactos ambientais (TOLMASQUIM, GUERREIRO \& GORINI, 2007).

Segundo dados da International Energy Agency (IEA), a matriz energética mundial é predominantemente produzida a partir fontes não renováveis. A produção de energia a partir de fontes renováveis representa apenas 13\% da matriz energética mundial (IEA, 2017).

Ao observar a participação das energias renováveis nos países integrantes da Organization for Economimic Co-operation and development (OECD), identifica-se uma participação ainda inferior, apenas 9,4\% da matriz energética é proveniente de fontes renováveis.

O Ministério de Minas e Energia (MME) destaca a elevada participação de fontes de energias renováveis na matriz energética brasileira. Segundo dados publicados no balanço Energético Nacional de 2018 , 43,2\% de toda energia produzida é de fonte renovável, uma das maiores participações mundiais (MME, 2018). Ao avaliar apenas a matriz elétrica brasileira essa participação é ainda maior, 80,4\% da energia elétrica produzida é proveniente de fontes renováveis, uma das maiores participações mundiais.

A participação de $23 \%$ de fontes renováveis na matriz elétrica dos países integrantes da OECD é a maior desde o início dos dados da série histórica que se iniciou em 1990. O aumento desta participação se deve principalmente à expansão de parques eólicos que cresceram a uma média anual de $24 \%$ e a energia solar fotovoltaica que cresceu em média 45\% ao ano (IEA, 2017).

Devido à elevada participação da fonte hidroelétrica na matriz elétrica brasileira, aproximadamente de 65\%, algumas fragilidades desta fonte foram ponderadas a partir de 2001. Devido à falta de chuvas, erros de operação dos reservatórios e baixos investimentos no setor, os brasileiros enfrentaram um racionamento de energia que foi conhecido popularmente como "crise do apagão" e colocou em dúvida a confiabilidade na fonte hidráulica, trazendo à tona a discussão da diversificação da matriz elétrica (TOLMASQUIM, 2000; MARENGO, et al., 2015).

A utilização de fontes alternativas de energia, como a solar e a eólica, é citada como opções para diversificação da matriz elétrica, assim como para redução no uso de combustíveis fósseis (MACHADO, BORBA \& MACIEL, 2016).

O Sol é a fonte de energia utilizada para alimentar os sistemas fotovoltaicos, considerado inesgotável do ponto de vista da longevidade humana e distribuído por todo planeta sem custos e resíduos, a energia solar fotovoltaica aparece como uma possibilidade para geração de energia limpa ao converter diretamente a radiação solar em energia elétrica. Neste contexto é possível considerar está fonte como uma das mais promissoras na geração de eletricidade (SCHIERMEIER, TOLLEFSON, SCULLY, WITZE \& MORTON, 2008).

Os custos dos sistemas fotovoltaicos diminuíram muito nos últimos anos e modificações nas legislações, como a ocorrida em 2012 por meio da resolução normativa ANEEL 482/2012 e sua respectiva modernização ANEEL 687/2015, favoreceram a expansão deste tipo de energia no país (MME, 2013).

A resolução normativa ANEEL 482/2012 possibilitou o consumidor comum gerar sua própria energia a partir de fontes renováveis, assim como fornecer o excedente de energia produzida para a rede de distribuição de energia. Este sistema foi denominado pela ANEEL de Sistema de Compensação de Energia Elétrica e é conhecido internacionalmente pelo termo Net Metering (ANEEL, 2015).

Para aumentar a disponibilidade de energia de maneira sustentável, alicerçado no tripé de sustentabilidade econômica, social e ambiental, é importante analisar um investimento considerando ao menos essas três perspectivas (MARCHIORO, DAHMER \& SOUZA, 2018). 
A ANEEL destaca que os custos de aquisição e eventuais linhas de financiamentos não são estabelecidos pela resolução normativa e devem ser avaliadas pelo usuário. A análise do retorno sobre o investimento dos sistemas fotovoltaicos também deve ser avaliadas individualmente, pois podem variar em função da região, Iocalização geográfica da instalação e das tarifas praticadas pelas concessionárias (ANEEL, 2015).

A decisão pela aquisição do sistema de energia solar fotovoltaica é do consumidor de energia e é formada por alguns fatores como conhecimento da tecnologia, conscientização ambiental e custo do sistema (MME, 2013).

Neste contexto, este artigo busca responder a seguinte pergunta de pesquisa: Qual a viabilidade financeira para instalação de um sistema fotovoltaico em uma residência unifamiliar localizada na região oeste da cidade de São Paulo? Sendo assim, este estudo tem como objetivo avaliar a viabilidade financeira para instalação de um sistema fotovoltaico em uma residência unifamiliar localizada na região oeste da cidade de São Paulo, utilizando como critério de decisão o tempo de retorno sobre o investimento.

A metodologia utilizada neste estudo é de natureza qualitativa com abordagem metodológica exploratória e descritiva. Análises técnicaseconômicas foram utilizadas para estimar com precisão as condicionantes envolvidas em uma análise de investimento. Os resultados desta análise serão comparados com a vida útil do equipamento e a taxa SELIC será utilizada como referencial à taxa mínima de atratividade (TMA).

\section{Referencial teórico}

\subsection{Matriz energética}

A matriz energética contempla todos os tipos de energias liberadas para serem transformadas, distribuídas e consumida sem diversas finalidades. A matriz energética é formada por fontes primárias de energias, como a solar, petróleo, biomassa, carvão, gás natural, hidráulica entre outras (MAUAD,
FERREIRA \& TRINDADE, 2017).

As fontes de energia podem ser divididas em renováveis e não-renováveis, dependo da fonte de obtenção. As fontes de energia renováveis utilizam recursos que possuem a capacidade de manter-se disponíveis por um longo prazo devido às características de renovação, ou inesgotáveis do ponto de vista da longevidade humana, como a radiação solar, ventos, água, biomassa e outros (MANTOVANI, 2016).

As fontes de energia não renováveis se encontram disponíveis de forma limitada na natureza e se extinguem após sua utilização, ou seja, uma vez esgotadas não poderão ser regeneradas. Pertencem a esse grupo os combustíveis fosseis e o urânio (MANTOVANI, 2016). A matriz energética mundial é predominantemente composta por fontes não renováveis. Segundo dados da International Energy Agency (IEA), a produção de energia a partir de fontes renováveis representa apenas 13\% da matriz energética mundial e nos países integrantes da Organization for Economimic Co-operation and development (OECD), identifica-se uma participação ainda inferior, apenas 9,4\% da matriz energética é proveniente de fontes renováveis (IEA, 2017).

O Brasil possui uma relativa vantagem competitiva no setor energético devido à abundância de recursos naturais, mas a exploração demanda estudos especiais para identificar a sustentabilidade social e ambiental (TOLMASQUIM, 2007). Esta relativa vantagem no setor energético pode ser identificada quando comparados a participação de energia renováveis na matriz energética brasileira. De acordo com dados publicados no balanço energético nacional (ano base 2017), 43,2\% de toda energia produzida no Brasil é a derivada de fontes renováveis, uma das maiores médias mundiais (MME, 2018).

\subsection{Matriz elétrica}

A matriz elétrica representa uma parte da matriz energética e pode ser produzida a partir de diversas fontes primárias renováveis e não-renováveis. Apesar dos recentes avanços na utilização de fontes renováveis, a utilização de fontes não-renováveis 
ainda representa $76,2 \%$ de toda energia elétrica produzida nos países da OECD (IEA 2017).

A energia solar fotovoltaica assume um importante destaque na matriz elétrica renovável da OECD com o maior crescimento médio anual entre todas as fontes renováveis. Crescendo a uma média anual de 43,3\%, essa fonte representa ainda uma pequena parcela entre as renováveis em termos absolutos. Porém, seu rápido crescimento traz boas expectativas na busca de alternativas aos tradicionais combustíveis fosseis responsáveis por elevada emissão de carbono e o aquecimento global (IEA 2017).

A análise dos dados sobre a participação de energias renováveis na matriz elétrica brasileira demonstra uma das maiores participações mundiais com 80,4\%. A fonte hidroelétrica é a que possui maior participação na matriz elétrica com aproximadamente $65,2 \%$, o gás natural ocupa a segunda posição com 10,5\%, a biomassa participa com $8,2 \%$, eólica $6,8 \%$ e derivados de petróleo 3,7\% (Tabela 1) (MME, 2018).

Essa elevada participação da fonte hidroelétrica na matriz elétrica brasileira é considerada positiva do ponto de vista da utilização de uma fonte renovável, mas por outro lado a elevada dependência de uma fonte de energia coloca em questão a diversificação da matriz elétrica (MARENGO et. al., 2015).

A utilização de outras fontes renováveis na matriz elétrica torna-se importante para atender a crescente demanda por energia elétrica e garantir a confiabilidade do sistema elétrico, oferecendo uma alternativa ao acionamento das termoelétricas durante a possibilidade de uma nova crise hídrica (ROSA \& GASPARIN, 2016).

Apesar da pequena participação da energia solar fotovoltaica no total da matriz elétrica renovável, apenas 0,1\%, o MME ressalta a importância dessa matriz energética e destaca que a energia solar fotovoltaica apresentou o maior crescimento percentual entre todas as fontes de energia (MME, 2018).

\subsection{Energia solar fotovoltaica}

Tabela 1. Participação por fonte na matriz elétrica brasileira, no ano base 2017 (MME, 2018).

\begin{tabular}{cc}
\hline Fonte & Participação \\
\hline Hidráulica & $65,2 \%$ \\
Gás Natural & $10,5 \%$ \\
Biomassa & $8,2 \%$ \\
Eólica & $6,8 \%$ \\
Carvão de derivados & $3,6 \%$ \\
Derivados de petróleo & $3,0 \%$ \\
Nuclear & $2,5 \%$ \\
Solar & $0,1 \%$ \\
\hline
\end{tabular}

A produção de eletricidade utilizando o sol como fonte foi observada pela primeira vez pelo físico francês Edmond Becquerel em 1839 ao observar que duas placas de latão imersas em um eletrólito líquido produziam eletricidade se expostas à luz solar. A este fenômeno foi dado o nome de efeito fotovoltaico. Em 1954, cientistas da Bell Labs, desenvolveram a primeira célula solar preparada a base de silício. A célula possuía eficiência de $6 \%$ e, desde então, as pesquisas no ramo cresceram progressivamente (KOMP, 1982).

Para conversão direta da radiação solar em energia elétrica em sistemas fotovoltaicos interligados à rede elétrica são necessários basicamente, painéis fotovoltaicos e um inversor de corrente (MACHADO \& MIRANDA, 2015).

Os painéis fotovoltaicos comercialmente disponíveis no mercado são basicamente compostos por células fotovoltaicas de silício monocristalino, silício policristalino ou de silício amorfo. As células de silício monocristalino apresentam a melhor eficiência, em torno de 12-15\%, as de silício policristalino entre $11-14 \%$ e as de silício amorfo entre 6-7\% (MORI et. al., 2007).

A energia produzida nos painéis fotovoltaicos é gerada corrente contínua (CC), o inversor de tensão transforma essa energia inicialmente produzida em corrente alternada (CA) para poder ser utilizada pelos equipamentos elétricos (MACHADO, 2015).

Os sistemas fotovoltaicos são considerados de baixo impacto ambiente durante seu funcionamento, trabalham de maneira estática, sem a emissão som e funciona sem queimar combustível (SAMPAIO \& GONZÁLEZ, 2017). 
Em 2015 a energia solar fotovoltaica teve destaque na matriz energética brasileira devido ao crescimento de 266,40\%\%. Este fenômeno de crescimento também é observado internacionalmente e, assim como no Brasil, recebe especial destaque nos balanços energéticos no mundo (MME \& EPM, 2016; IEA 2017).

O Ministério de Minas e Energia (MME) entende que o a disseminação da energia fotovoltaica distribuída se deve à possibilidade de créditos na conta de energia elétrica regulamentados na resolução normativa ANEEL 482/2012, assim como pela difusão desta tecnologia, conscientização ambiental e diminuição de custo de aquisição e instalação dos sistemas fotovoltaicos (MME, 2016).

\subsection{Regulamentação da geração distribuída no Brasil}

Em abril de 2012, entrou em vigor a resolução normativa ANEEL n 482/2012 que fundamenta as diretrizes da microgeração e minigeração distribuída no Brasil. Este documento fundamental no campo das políticas públicas do setor energético inaugurou o novo modelo do sistema elétrico brasileiro, permitindo que o consumidor possa gerar sua própria energia elétrica a partir de fontes renováveis ou cogeração qualificada, assim como fornecer o excedente de energia produzida para a rede de distribuição de energia (ANEEL, 2015).

A microgeração distribuída se caracteriza por uma central geradora de energia elétrica que utiliza fontes renováveis de energia com potência instalada menor ou igual a $75 \mathrm{~kW}$, conectada à rede elétrica por meio de uma unidade consumidora. Para fontes hídricas a resolução permite uma potência instalada de até $5 \mathrm{MW}$, conectada à rede elétrica por uma unidade consumidora (ANEEL, 2017).

Quando a quantidade de energia gerada em determinado período é superior à energia consumida, o consumidor adiciona créditos que serão descontados no momento que a geração é inferior ao consumo. Essa operação de crédito e débito de energia é realizada por meio de empréstimo gratuito para distribuidora local e posteriormente compensada com o consumo de energia elétrica ativa, nunca com crédito ou débito de importâncias monetárias. Esse sistema é conhecido internacionalmente pelo termo em inglês Net Metering. No Brasil esse sistema é denominado de Sistema de compensação de energia elétrica (Figura 1) (ANEEL, 2015).

A geração distribuída se destaca pelo potencial benefício proporcionado ao sistema elétrico como adiamento de investimentos na expansão dos sistemas de transmissão e distribuição,

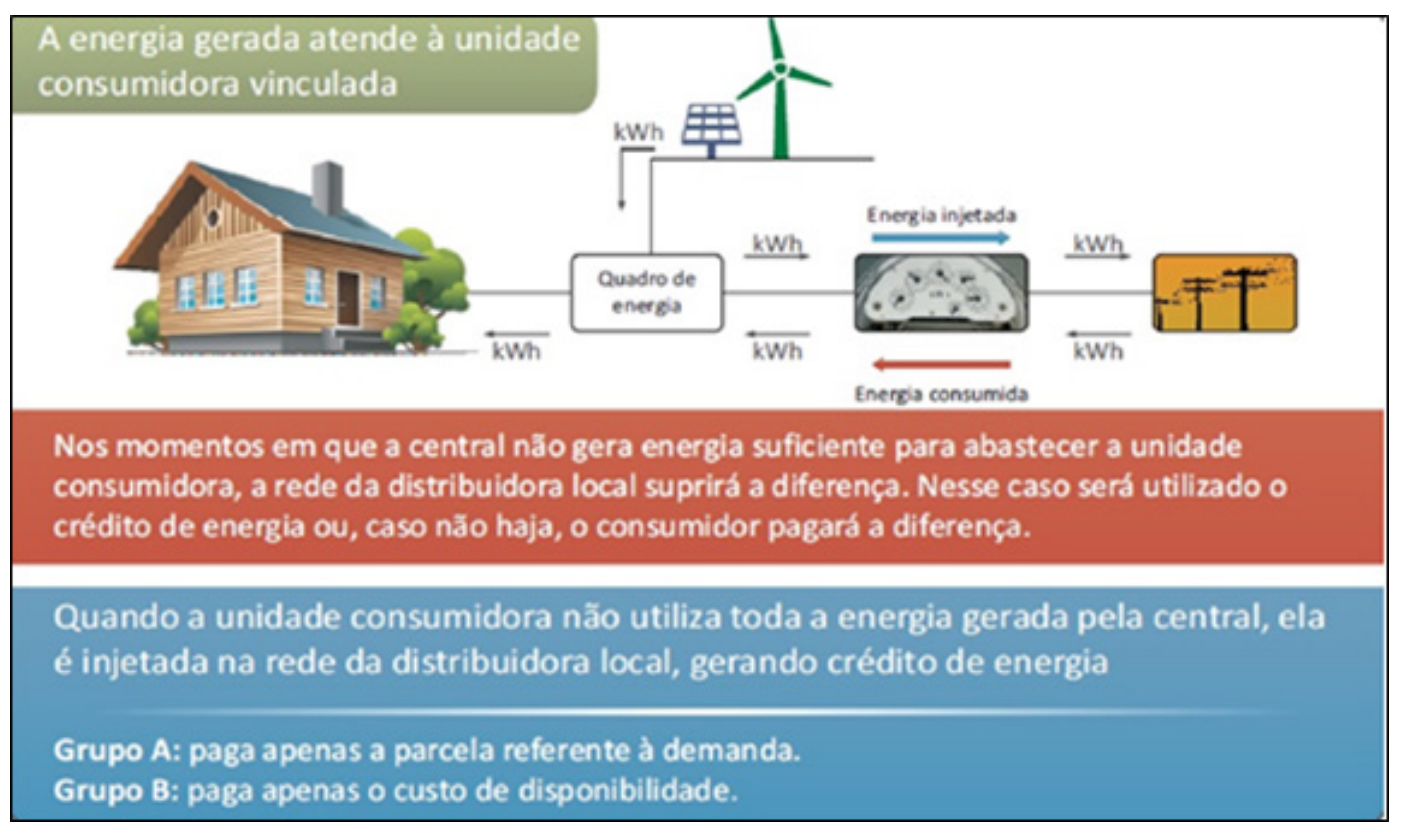

Fig. 1. Geração fotovoltaica distribuída (ANEEL, 2016). 
minimização das perdas, baixo impacto ambiental e diversificação da matriz energética (ANEEL, 2015).

A iniciativa da instalação e a análise do custo versus benefício devem ser do consumidor, uma vez que cada caso envolve características muito particulares como tipo de tecnologia, tarifa local de energia, Iocalização e custos de adequação de infraestrutura (ANEEL, 2017).

Neto (2014) destaca que a resolução normativa ANEEL 482/2012 foi um importante passo na regulamentação deste setor para o Brasil, mas que essa regulamentação isolada de campanhas que mobilizem o cidadão comum a conhecer e instalar estes sistemas não terá a mesma efetividade.

\subsection{Conceituação de finanças e do projeto de investimento}

Finanças são processos decisórios que envolvem basicamente uma decisão a ser tomada com um determinado capital que deverá criar valor. A criação de valor é definida como a capacidade de produzir resultados financeiros capazes de superar o custo do capital investido (FILHO, SOUZA, GONÇALVES \& CURY, 2012)

Um projeto de investimento pode ser descrito de maneira simplificada como um conjunto sistemático de informações que serão utilizados de base para a tomada de decisão relativa à alocação de capital (LUCAS, 2016).

Para uma boa tomada de decisão do ponto de vista financeiro, deve-se identificar os aspectos mais relevantes envolvidos no projeto, como a relação entre o risco e o retorno sobre o investimento, assim como o fluxo de caixa. Desta forma é possível mitigar riscos na tomada de decisão de investimento (FILHO et. al., 2012)

A seguir são apresentados também conceitos amplamente utilizados nas análises de viabilidade de investimentos que utilizam a matemática financeira para projetar o valor do dinheiro no tempo.

A Taxa Mínima de Atratividade (TMA), também conhecida pelo termo em inglês capital asset pricing model (CAPM), pode ser definida como a remuneração mínima esperada por um ativo. É comum utilizar nestes casos como referência um ativo livre de risco (FILHO et. al., 2012).

O Valor Presente Líquido (VPL), ou em inglês net present value (NPV), pode ser considerado como um dos critérios mais rigorosos para comparação de projetos diferentes, mas com o mesmo horizonte de tempo. Matematicamente o VPL é o valor presente equivalente de um fluxo de caixa de projeto calculado a uma determinada taxa de desconto. Desta forma se o VPL for positivo na análise de projetos, significa que ele possui atratividade (FILHO et. al., 2012).

O Payback Descontado (PBD), em termos práticos apresenta uma perspectiva do tempo de recuperação do investimento, levando em conta o valor do capital no tempo ao utilizar a taxa mínima de atratividade no cálculo. Pode apontar riscos caso o período de permanência do capital for muito prolongado em um determinado projeto. Este método deve ser utilizado em conjunto com outros métodos, pois em diversos casos não é possível identificar a criação de valor para o investidor (FILHO et. al., 2012).

\section{Metodologia}

Este trabalho possui natureza qualitativa com abordagem metodológica descritiva e exploratória. A natureza qualitativa se caracteriza pela descrição, interpretação e compreensão de fatos e fenômenos, utilizando-se do ambiente natural como fonte de dados. O pesquisador é instrumento chave para realização deste tipo de pesquisa, auxiliando no entendimento, compreensão e descrição dos fenômenos (MARTINS \& THEÓPHILO, 2009).

Os trabalhos descritivos e exploratórios expõem uma determinada população ou fenômeno e podem ampliar-se estabelecendo correlações bem como ser utilizado de base para explicar fenômenos como o descrito neste trabalho (VERGARA, 1990).

$\mathrm{Na}$ fase de coleta de dados primários as evidências que compõe o material sobre o estudo foram coletadas diretamente das fontes, empresas integradoras que comercializam e instalam os 
sistemas fotovoltaicos. Estes dados são compostos por orçamentos e projetos técnicos utilizados para avaliação do investimento nos sistemas fotovoltaicos (YIN, 2015).

Os dados secundários foram obtidos por meio de levantamentos bibliográficos em revistas, livros, periódicos, jornais, sites, legislações, catálogos e congressos, em busca de analisar, explicar e contribuir com tema objeto desta pesquisa.

Foi avaliada a viabilidade financeira para instalação de um sistema fotovoltaico em uma residência unifamiliar localizada na região oeste da cidade de São Paulo (SP), utilizando análises técnicas-econômicas para estimar com precisão as condicionantes envolvidas em uma análise de investimento.

\subsection{Caracterização das empresas integradoras e orçamentos}

As empresas integradoras são empresas que comercializam, dimensionam, instalam e realizam o projeto de regularização junto à distribuidora de energia elétrica dos sistemas fotovoltaicos.

As empresas integradoras que participaram deste trabalho estão localizadas na região da grande São Paulo (SP). Essa região engloba a cidade São Paulo assim como as cidades localizadas no seu entorno, como Osasco, Guarulhos e São Bernardo do Campo.

Para solicitação dos orçamentos foram fornecidos para todas as empresas integradoras os mesmos dados técnicos da residência escolhida para estudo, assim como a mesma condição para pagamento, no caso deste estudo à vista.

Foi solicitado também a mesma garantia do sistema fotovoltaico, 25 anos para os painéis fotovoltaicos e 5 anos para o inversor de corrente. Contudo a expectativa de funcionamento do sistema como um todo é de pelo menos 25 anos.

As empresas integradoras possuem particularidades no desenvolvimento do projeto e por se tratar de empresas de iniciativa privada aplicam diferentes de margens de lucro.

Contudo, para a escolha da empresa integradora foi feito uma análise de custo versus benefício, levando em conta além do custo do sistema fotovoltaico os benefícios oferecidos pelas empresas. A empresa escolhida apresentou um orçamento de R\$12.996,00 (doze mil, novecentos e noventa e seis reais).

\subsection{Caracterização da residência em estudo}

O desenvolvimento deste estudo foi conduzido na cidade São Paulo, a maior e uma das mais importantes cidades do estado de São Paulo. Do ponto de vista econômico é também a mais importantes do país (MITSCHER, 2012).

A cidade também abriga uma das maiores distribuidoras de energias elétrica do país, a Eletropaulo, que devido ao seu elevado número de consumidores, tem potencial de ser uma das maiores distribuidoras de energia fotovoltaica distribuída (MIRANDA, 2014).

A residência unifamiliar utilizada neste estudo fica localizada na região oeste da cidade de São Paulo, com moradores com idade entre 20 e 65 anos. A casa é térrea e o telhado é do tipo laje e suporta a estrutura do sistema fotovoltaico com relativa simplicidade, ou seja, não serão necessárias obras de reforço ou adaptação, apenas a instalação dos suportes dos painéis fotovoltaicos.

Uma das motivações para a escolha desta casa foi à ausência de vizinhos com edificações elevadas, pois poderiam produzir sombra sobre o telhado, ocasionando distorções no dimensionamento do sistema fotovoltaico e na previsão de produção da energia fotovoltaica.

A residência está ligada no sistema bifásico e o consumo médio mensal de energia elétrica é de $240 \mathrm{kWh}$.

\subsection{Características do sistema fotovoltaico}

O sistema dimensionado pela empresa é interligado a rede elétrica, ou seja, utiliza os benefícios sistema de compensação de energia elétrica característicos a este tipo de sistema. Possui potência de 1,98 kWp para o primeiro ano, contudo é esperado uma perda de 0,5\% de produção ao ano. Esta perda será considerada no fluxo de caixa 
projetado. A expectativa de produção do primeiro ano é de $2.568 \mathrm{kWh}$, que resulta em uma média mensal de $214 \mathrm{kWh}$.

O sistema é composto por 6 painéis fotovoltaicos de $330 \mathrm{~W}$ do tipo policristalino, inversor, quadro de proteção, estruturas de fixação e material elétrico, a mão de obra e o frete estão inclusos no valor total sistema.

\section{Resultados e discussão}

O Valor Presente Líquido (VPL) pode ser considerado como um dos critérios mais rigorosos para comparação de projetos diferentes em um mesmo horizonte de tempo. De maneira geral é muito aceito porque traz a valor presente fluxos futuros descontados de uma taxa mínima para compensar os riscos no investimento (FILHO et. al., 2012).

No caso deste estudo foi utilizado à taxa básica de juros, SELIC, que serve de referência aos investimentos de renda fixa, ou seja, de baixo de risco.

Para analisar o resultado de maneira conservadora, foi aplicada uma Taxa Mínima de Atratividade (TMA), equivalente a $100 \%$ da SELIC, atualmente em 6,5\% ao ano. Desta forma é possível comparar a atratividade do investimento em relação à maioria dos investimentos financeiros de renda fixa, como a Poupança e os Certificados de Depósitos Bancários (CDB), levando em conta um capital igual ao investimento inicial de R\$12.996,00, utilizado para aquisição do sistema fotovoltaico (LUCAS, 2016). Para calcular o VPL, utiliza-se equação 1.

$V P L=\left(\frac{F C 1}{(1+i)}+\frac{F C 2}{(1+i) 2}+\cdots+\frac{F C N}{(1+i) N}\right)-F C_{\text {inicial }}$

Onde:

$\mathrm{FC}=$ Fluxo de caixa

i = Taxa mínima de atratividade

Os dados utilizados para desenvolvimento do cálculo do VPL foram extraídos da tabela 2, onde FC1, FC2 e FCN representam o valor do fluxo de caixa nos anos 1, 2 e "N" os anos sucessivos até o vigésimo quinto.
O valor de $\mathrm{FC} 1 /(1+\mathrm{i})$, é o fluxo de caixa descontado do ano 1, igual a R\$ 1.478,25. O valor de FC2/(1+i)2 é o fluxo de caixa descontado do ano 2 e assim sucessivamente. A somatória de todos os fluxos de caixas descontados e posteriormente subtraído do capital inicialmente investido é igual ao valor do $\mathrm{VPL}=13 \cdot 761,43$.

Para uma visualização mais detalhada da análise de viabilidade econômica do investimento, foi elaborada uma tabela com o fluxo de caixa descontado da TMA (Tabela 2) e um gráfico representando o tempo necessário para o retorno sobre o investimento, Payback Descontado (Figura 2) até $\circ 25^{\circ}$ ano, que foi considerado como o tempo de vida do projeto.

Conforme informações fornecidas pelo fabricante dos painéis fotovoltaicos, ocorre uma perda de eficiência de 0,5\% ao ano na produção de energia, em função da longevidade do projeto este fator também foi considerado no fluxo de caixa projetado.

A tarifa aplicada para a base de cálculo da remuneração da geração de energia elétrica fotovoltaica foi a tarifa relativa ao mês de junho de 2018, praticada pela concessionária que atende o domicílio em estudo, descontadas das taxas de iluminação pública e da bandeira tarifária vermelha. O valor auferido foi de R\$ 0,63/kWh (sessenta e três centavos por kWh).

É importante destacar que mesmo que a produção de energia elétrica seja igual ao consumo, as unidades geradoras conectadas a rede de distribuição deverão pagar uma taxa denominada de custo de disponibilidade. No caso em estudo, a residência está conectada em baixa tensão em um sistema bifásico e a cobrando o valor será equivalente a $50 \mathrm{kWh} / \mathrm{mês}$ (ANEEL, 2015). A cobrança da taxa de disponibilidade, assim como da taxa de iluminação, pública estão descontadas dos fluxos projetados.

O valor da tarifa de energia elétrica foi corrigido anualmente na planilha de fluxos projetados, com base no valor definido no regime de metas de inflação do Banco Central. Embora este valor, hoje em $4 \%$ ao ano, ser inferior da média das últimas correções, ele foi escolhido para manter o cálculo 
Tabela 2. Fluxo de caixa projetado.

\begin{tabular}{|c|c|c|c|c|c|c|c|c|}
\hline Ano & $\begin{array}{c}\text { Energia } \\
\text { produzida no } \\
\text { ano (kWh) }\end{array}$ & $\begin{array}{c}\text { Tarifa } \\
\text { (R\$) }\end{array}$ & $\begin{array}{c}\text { Receita de } \\
\text { energia no } \\
\text { ano (R\$) }\end{array}$ & $\begin{array}{c}\text { Custo de } \\
\text { disponibilidade } \\
\text { (R\$) }\end{array}$ & $\begin{array}{c}\text { Iluminação } \\
\text { pública + outras } \\
\text { tarifas (R\$) }\end{array}$ & $\begin{array}{l}\text { Fluxo de } \\
\text { caixa (R\$) }\end{array}$ & $\begin{array}{c}\text { Fluxo de caixa } \\
\text { descontado } \\
\text { (R\$) }\end{array}$ & $\begin{array}{c}\text { Payback } \\
\text { descontado } \\
(\mathrm{R} \$)\end{array}$ \\
\hline 0 & & & & & & $-12.996,00$ & $-12.996,00$ & - 12.996,00 \\
\hline 1 & 2.568 & 0,63 & $1.617,84$ & 31,50 & 12,00 & $1.574,34$ & $1.478,25$ & $-11.517,75$ \\
\hline 2 & 2.555 & 0,66 & $1.674,14$ & 32,76 & 12,05 & $1.629,33$ & $1.436,52$ & - 10.081,23 \\
\hline 3 & 2.542 & 0,68 & $1.732,40$ & 34,07 & 12,10 & $1.686,23$ & $1.395,95$ & $-8.685,28$ \\
\hline 4 & 2.530 & 0,71 & $1.792,69$ & 35,43 & 12,14 & $1.745,11$ & $1.356,51$ & - 7.328,77 \\
\hline 5 & 2.517 & 0,74 & $1.855,07$ & 36,85 & 12,19 & $1.806,03$ & $1.318,19$ & $-6.010,58$ \\
\hline 6 & 2.504 & 0,77 & $1.919,63$ & 38,32 & 12,24 & $1.869,06$ & $1.280,93$ & $-4.729,65$ \\
\hline 7 & 2.492 & 0,80 & $1.986,43$ & 39,86 & 12,29 & $1.934,29$ & $1.244,72$ & $-3.484,92$ \\
\hline 8 & 2.479 & 0,83 & $2.055,56$ & 41,45 & 12,34 & $2.001,77$ & $1.209,53$ & $-2.275,39$ \\
\hline 9 & 2.467 & 0,86 & $2.127,10$ & 43,11 & 12,39 & $2.071,60$ & $1.175,33$ & $-1.100,06$ \\
\hline 10 & 2.455 & 0,90 & $2.201,12$ & 44,83 & 12,44 & $2.143,84$ & $1.142,08$ & 42,02 \\
\hline 11 & 2.442 & 0,93 & $2.277,72$ & 46,63 & 12,49 & $2.218,60$ & $1.109,77$ & $1.151,79$ \\
\hline 12 & 2.430 & 0,97 & $2.356,98$ & 48,49 & 12,54 & $2.295,95$ & $1.078,37$ & $2.230,16$ \\
\hline 13 & 2.418 & 1,01 & $2.439,00$ & 50,43 & 12,59 & $2.375,98$ & $1.047,85$ & $3.278,01$ \\
\hline 14 & 2.406 & 1,05 & $2.523,88$ & 52,45 & 12,64 & $2.458,79$ & $1.018,19$ & $4.296,19$ \\
\hline 15 & 2.394 & 1,09 & $2.611,71$ & 54,55 & 12,69 & $2.544,48$ & 989,36 & $5.285,55$ \\
\hline 16 & 2.382 & 1,13 & $2.702,60$ & 56,73 & 12,74 & $2.633,13$ & 961,34 & $6.246,90$ \\
\hline 17 & 2.370 & 1,18 & $2.796,65$ & 59,00 & 12,79 & $2.724,86$ & 934,12 & 7.181,01 \\
\hline 18 & 2.358 & 1,23 & $2.893,97$ & 61,36 & 12,84 & $2.819,77$ & 907,66 & 8.088,67 \\
\hline 19 & 2.346 & 1,28 & $2.994,68$ & 63,81 & 12,89 & $2.917,98$ & 881,94 & $8.970,61$ \\
\hline 20 & 2.335 & 1,33 & $3.098,90$ & 66,37 & 12,95 & $3.019,59$ & 856,95 & $9.827,56$ \\
\hline 21 & 2.323 & 1,38 & $3.206,74$ & 69,02 & 13,00 & $3.124,72$ & 832,66 & $10.660,22$ \\
\hline 22 & 2.311 & 1,44 & $3.318,34$ & 71,78 & 13,05 & $3.233,51$ & 809,06 & $11.469,29$ \\
\hline 23 & 2.300 & 1,49 & $3.433,81$ & 74,65 & 13,10 & $3.346,06$ & 786,13 & $12.255,41$ \\
\hline 24 & 2.288 & 1,55 & $3.553,31$ & 77,64 & 13,15 & $3.462,52$ & 763,84 & $13.019,25$ \\
\hline 25 & 2.277 & 1,61 & $3.676,97$ & 80,74 & 13,21 & $3.583,02$ & 742,18 & $13.761,43$ \\
\hline
\end{tabular}

$\mathrm{TMA}=6,50 \%, \mathrm{VPL}=\mathrm{R} \$ 13.761,43$

de retorno sobre o investimento em um patamar conservador.

De acordo com as características encontradas na região da cidade de São Paulo, o Payback Descontado, ou seja, o tempo necessário para recuperar o investimento, resultou em 11 anos. Esse resultado pode ser considerado interessante, uma vez que o tempo do projeto de investimento é de 25 anos.

Contudo, o cálculo do Payback Descontado deve ser utilizado em conjunto com outro método, para poder identificar a criação de valor do projeto. Neste caso foi utilizado o VPL e o valor encontrado foi de RS 13.761,43.
Esta análise de investimento apresentou resultados interessantes sob as duas perspectivas, ao retornar todo o valor investido no décimo primeiro ano e a geração de lucro de R\$13.761,43 ao final do vigésimo quinto ano.

É importante destacar que algumas empresas integradoras utilizam o Payback Simples como critério de cálculo, desconsiderando o princípio básico financeiro onde não é possível somar dinheiro em tempos diferentes (FILHO et. al., 2012). Desta forma, o resultado do tempo necessário para retorno sobre o investimento pode cair pela metade, mas de maneira errônea.

A aplicação de conceitos financeiro adequados em 


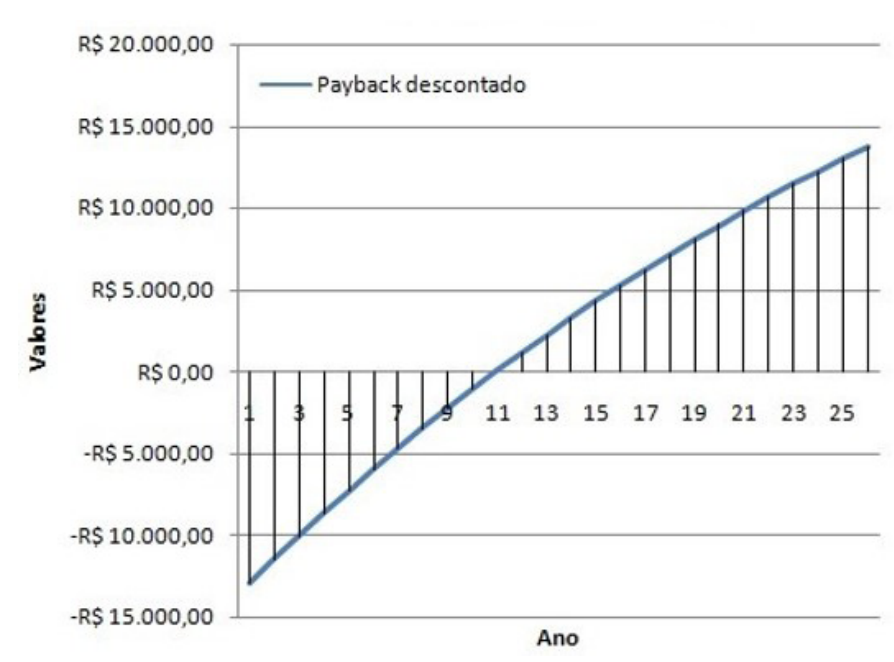

Fig. 2. Payback descontado.

análises de viabilidade econômica, como o VPL e o Payback Descontado, podem auxiliar o consumidor final na tomada de decisão de investimento em um sistema fotovoltaico, uma vez que a decisão fica a critério do consumidor final, que deve ponderar a relação do custo versus benefício, diferente em de cada região.

\section{Conclusões}

Diante das análises financeiras realizadas, é possível afirmar que o projeto de investimento de instalação de um sistema fotovoltaico em uma residência unifamiliar na região oeste da cidade de São Paulo é viável economicamente.

O valor calculado do VPL ao final do $25^{\circ}$ ano é de $\mathrm{R} \$ 13.761,43$, resultado que indica viabilidade do projeto e geração de valor ao investidor. O VPL pode ser considerado com um dos critérios mais rigorosos na análise de investimentos, pois considera o valor do dinheiro no tempo, descontado de uma taxa mínima de atratividade (TMA) livre de risco, neste caso a SELIC, atualmente em 6,5\%.

Ao analisar o tempo do retorno sobre o investimento, Payback Descontado, identificou-se que no $11^{\circ}$ ano ocorre o retorno de todo capital investido. Levando em conta que o sistema possui uma vida útil de aproximadamente 25 anos, o investimento também se demonstra viável por esta perspectiva.

É importante destacar que estes cálculos foram realizados levando em conta o cenário nacional atuais. Alterações da SELIC e reajustes da energia elétrica acima da inflação podem alterar os resultados encontrados, tornando o projeto mais atrativo em alguns casos e menos atrativos em outros.

Contudo é importante ressaltar que os benefícios relativos à diversificação da matriz energética brasileira e a utilização de uma fonte renovável de energia para os aspectos relacionados a sustentabilidade, que engloba os eixos ambiental, econômico e social.

\section{Referências bibliográficas}

AGÊNCIA NACIONAL DE ENERGIA ELÉTRICA ANEEL. Resolução Normativa N 687, 2015.

AGÊNCIA NACIONAL DE ENERGIA ELÉTRICA $A N E E L$. Micro e minigeração distribuída, sistema de compensação de energia elétrica. Cadernos temáticos ANEEL, 2016.

AGÊNCIA NACIONAL DE ENERGIA ELÉTRICA ANEEL. Perguntas e respostas sobre a aplicação da Resolução Normativa N482/20012, 2017.

FILHO, J. C. F. A.; SOUZA, C. P., GONÇALVES, D. A.; CURY, M. V. Q. Finanças Corporativas. FGV Editora, RJ. 2012.

INTERNATIONAL ENERGY AGENCY. World Energy Balances: An Overview. 2017.

KOMP, R. J. Practical photovoltaics: electricity from solar cells. Aatec Publications. 1982.

LUCAS, E. C. Finanças corporativas. Fundação Getúlio Vargas, SP. 2016.

MACHADO, I. S.; BORBA, B. S. M. C.; MACIEL, R. S. Modeling distributed PV market and its impacts on distribution system: A Brazilian case study. IEEE Latin America Transaction, v. 14, n. 11, p. 45204526, 2016.

MACHADO, C. T.; MIRANDA, F. S. Energia fotovoltaica: Uma breve revisão. Revista Virtual de Química, v. 
7, n. 1, p. 126-143. 2015.

MANTOVANI, P. R. A.; NEUMANN, P. N.; EDLER, M. A. R. Matriz Energética Brasileira: Em busca de uma nova alternativa. Revista Interdisciplinar de Ensino, Pesquisa e Extensão, v. 4, n. 1, p. 2016.

MARENGO, J. A. et al. A seca e a crise hídrica de 2014-2015 em São Paulo. Revista USP, n. 106, p. 31-44, 2015.

MARCHIORO, A. F.; DAHMER, R. D.; SOUZA, R. C. Metodologia para análise da viabilidade técnicaeconômica para geração de energia fotovoltaica. VII Congresso de Energia Solar, Gramado, RS, Brasil. 2018.

MARTINS, G. A.; THEÓPHILO, C. R. Metodologia da Investigação Científica para Ciências Sociais Aplicadas, $2^{a}$ ed., São Paulo, Atlas S.A. 2009.

MAUAD, F. F.; FERREIRA, L. C.; TRINDADE, T. C. G. Energia renovável no Brasil. Análise das principais fontes energéticas renováveis brasileiras. 2017. Recuperado de: http://www.livrosabertos.sibi.usp. br/portaldelivrosUSP/catalog/view/168/154/740-1

MINISTÉRIO DE MINAS E ENERGIA \& EMPRESA DE PESQUISA ENERGÉTICA. Balanço Energético Nacional 2018, Relatório Síntese ano base 2017. 2018.

MINISTÉRIO DE MINAS E ENERGIA. Nota técnica DEA 28/13, Projeção da demanda de energia elétrica para os próximos 10 anos (2014-2023). 2013.

MIRANDA, R. F. C.; SZKLO, A.; SCHAEFFER, R. Technical-economic potential of PV systems on Brazilian rooftop. Renewable Energy. v. 75, p. $694-$ 713, 2015.

MITSCHER, M.; RUTHER, R. Economic performance and policies for grid-connected residential solar photovoltaic systems in Brazil. Energy Policy, v. 49, n. C, p. 688-694. 2012.
Metalurgia do Silício: Processos de Obtenção e impactos ambientais, CETEM/MCT. 2007.

ROSA, A. R.; GASPARIN, F. P. Panorama da energia solar fotovoltaica no Brasil. Revista brasileira de energia solar. v. 7, n. 2, p. 140 - 147, 2016.

SAMPAIO, P. G. V.; GONZÁLEZ, M. O. A. Photovoltaic solar energy: Conceptual framework. Renewable and Sustainable Energy Reviews, v. 74, p. 590601, 2017.

SCHIERMEIER, Q. et al. Electricity without carbon. Nature, v. 453, p. 816-823, 2008.

TOLMASQUIM, M. T. As origens da crise energética brasileira. Ambiente \& Sociedade. Ano III - No 6/7 - 2000.

TOLMASQUIM, M. T.; GUERREIRO, A.; GORINI, R. Matriz energética brasileira: Uma perspectiva. CEBRAP, v. 79, p. 47-69, 2007.

VERGARA, S. C. Tipos de Pesquisa em Administração. Cadernos da Escola Brasileira de Administração Pública da Fundação Getúlio Vargas, p. 1-21, 1990.

YIN, R. K. Estudo de Caso: Planejamento e método. $5^{a}$ ed. Porto Alegre. Bookman. 2015. 